\title{
An assessment On Cause, Symptoms \& Treatment for Ovarian Cancer
}

\author{
Geetika Arora and Sumita Malhotra \\ Department of Obstetrics and Gynaecology Shree Guru Gobind \\ Singh Tricentary University, Gurugram, Haryana, India \\ Corresponding author email: drgeetikaarorabhatia@gmail.com
}

\begin{abstract}
As technology is increasing day by day, humans are getting affected by the side effects of these technology. Earlier the manual hard work was done by most of the people but now a day people are facing lot of health issues due to getting habitual of advance automatic devices. No doubts, smart gadgets reduce the human effort in daily life but, it is not wrong to say that being habitual of everything is bad even for health as well. In this paper some of causes, symptoms and treatments of ovarian cancer has been discussed in order to spread awareness regarding prevention and precautions that one should take. An assessment has been done on randomly selected women at nearby metro station by asking them few questions.For future perspective, spreading knowledge and awareness regarding women health and ovarian cancer may be proven as a big step towards healthy life.
\end{abstract}

\section{KEY WORDS: CAUSE\& EFFECT, HEALTH ISSUES, METHODS OF TREATMENT, PHYSICAL ACTIVITIES}

\section{INTRODUCTION}

\subsection{Ovaraian Cancer}

Ovarian cancer is one the deadliest disease found in females these days. In female's body, a part of reproductive system is known as ovaries that releases eggs in every cycle. Cells are the most fundamental living unit of human body that multiplies itself to form a complete body organ. At the time of development of a baby in womb of mother, the initial stage of development of the baby organs and body parts consist of cell multiplication process in which, cells divide in two and then in four to form a cluster of cells that plays a vital role in development of body. these cells have some mutation process which follows a pattern \& if these pattern disturbs the balance of whole body.

In regards of ovarian cancer, the false egg forms which become cyst. These cysts can be of many types that may be

Biosc Biotech Res Comm P-ISSN: 0974-6455 E-ISSN: 2321-4007

\section{crossef}

Identifiers and Pagination

Year: 2021 Vol: 14 No (6) Special Issue

Pages: $356-361$
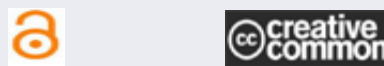

Article Information

Received: 14 $4^{\text {th }}$ May 2021

This is an open access article under Creative

Commons License Attribn 4.0 Intl (CC-BY).

DOI: http://dx.doi.org/10.21786/bbrc/14.75 self-dissolvable or maybe not. Some of those cyst become big and disturb the normal functioning of ovaries. Therefore, we can say that ovarian cancer is caused by uncontrolled mutation / division of abnormal cells formation in ovaries. In any type of cancer, abnormal cells increase in body and kills the normal cells which are the basic life unit in human body(R. Forstner et. at. (2020)).

\subsection{Types Of Ovaraian Cancer}

- Epithelial ovarian cancer (EOC)

- Ovarian low malignant potential tumor also named as borderline tumor,(OLMPT)

- Germ cell ovarian cancer

- Stromal ovarian cancer(V. W. Chen et. at. (2003).

\subsection{Factors At Risk}

- Less chances of getting pregnant.

- Reduced chances for breastfeeding.

- Oral contraceptives usage is at high risk.

- Females if developing ovarian cancer cells, are at risk of post-menopausal stage

- Increased risk for genetic mutation like BRCA.

- Family history regarding breast, ovarian colon cancer(D. M. Twickler et. at. (2010)).

1.4. Symptoms Of Ovarian Cancer: Cancer is one the most dangerous disease that cannot be cured properly, many 
researchers have been working on this disease to find some solution and medication to cure this but, everyone body has different way to respond to cancer cells. Immunity level also differ from person to person therefore, symptoms also vary. Some of the common symptoms has been listed below:

- Swelling on lower stomach is generally found in females that are about to develop cancer in future.

- Enlargement of abdominal area is one of the most common symptoms of ovarian cancer.

- Ovarian cancer is located and initiated only from ovaries which results in pain during intercourse as well.

- Sometimes vaginal bleeding is experienced by females that are about to develop ovarian cancer.

- Constipation, pelvic pain, back pain are most common features of ovarian cancer that anyone can observe in their body.

- Fatigue, indigestion, bloating, unable to eat normally are some of the common noticeable symptoms regarding ovarian cancer.

- There might be changes in bowel and bladder related habits.

- Body shape changes \& thus clothes not well fitted on body(S. H. Olson et. at. (2001)).

\subsection{Causes of ovarian cancer}

- PCOD: Poly cystic ovarian disease is one of the most common and major case of ovarian cancer which is caused due to bad lifestyle and wrong eating habits. In this PCOD, ovary size gets enlarged and not able to produce proper eggs which hamper the pregnancy potential.

- $\mathrm{Al}$ aluminum is one the major factor that cause cancer due to long term usage in cooking. Aluminum is a metal when al utensils are used in cooking they heat up at high temperature. Metals release ions when get energy and those ions is mixed in food that is cooked in it, which we eat which hamper our health.

- Developing unhealthy eating habits is also a major cause of developing different type of cancer. Specifically junk food that increase weight and deposit unsaturated fat in body that is not easily melted which increase weight and may cause PCOD.

- Smoking, lack of vitamins and proteins and essential mineral that may leads to malnutrition in teenage females and in long terms it is not a sign of good and healthy lifestyle(J.S.G. Biggs et. at. (1981).

1.6. Stages Of Ovaraian Cancer: This is well known to almost all that cancer has its own stages that describes the risk of life and patient's death as well. for how long the patient is going to survive with cancer properties. There are mainly 4 stages in ovarian cancer that has been illustrated in Figure 1 , 2, $3 \& 4$ that has own properties on the basis of how much, cancer has been spread in body(U.A. Matulonis et. at. (2016). In first stage, of ovarian cancer the cancer cells cover almost any one of the ovary and there may be chances of cancer cells to cover the second ovary as well along with fallopian tubes that are at major risk. In second stage of ovarian cancer, the cancer cells manipulate and alter the functioning of not only both ovaries but fallopian tubes as well along with some of the pelvic organs like uterus. In third stage of ovarian cancer, the most critical stage of any cancer in which, a visible tumor is appeared on the surface of liver and in lining of ovaries. Which increases at a very rapid rate and covers almost complete pelvic region.

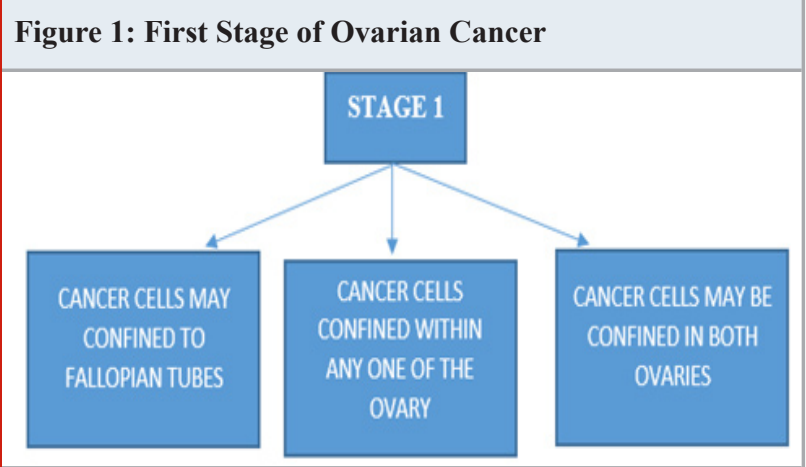

Figure 2: Second Stage of Ovarian Cancer

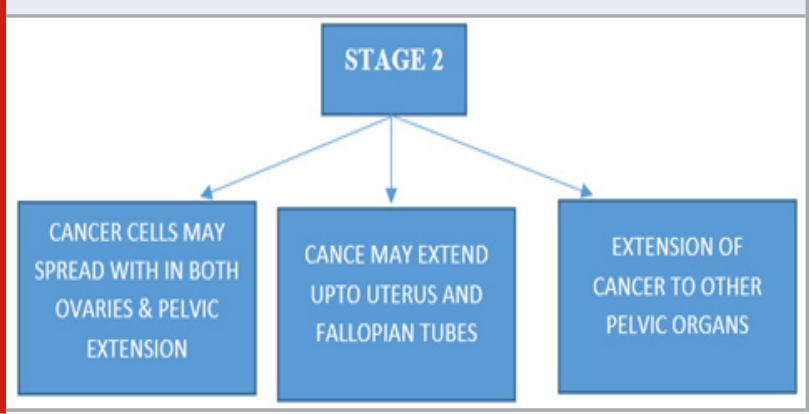

Figure 3: Third stage of ovarian cancer

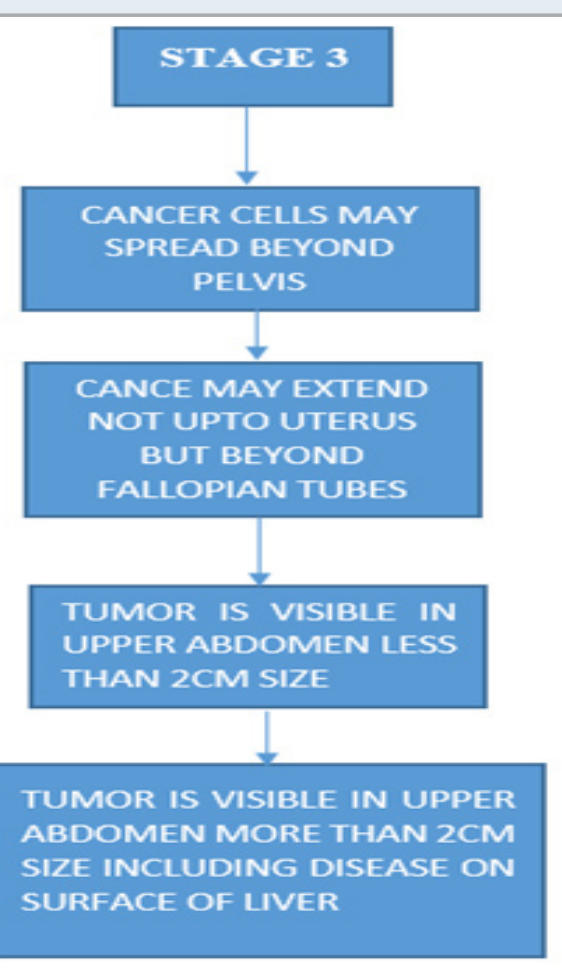


2. Case Study: According to a statistic in 2018, 22,240 cases have been found of ovarian cancer that has been diagnosed. Out of these cases, 14,070 patients have been died due to ovarian cancer. This data is associated in US patients only. From here, we can estimate that all over world, how many females are affected due to this ovarian cancer. However, mortality rate has been reduced by $29 \%$ in 2014 . Later this rate was reduced to $33 \%$ in 2015 . According to author $90 \%$ cases are related to epithelial type(L. A. Torre et. at. (2018)).

In forth stage it is difficult to save the patient as it is the deadliest stage of any cancer, in this stage, cancer cells spread in all over the pelvic region and reproductive region. Also, these cancer cells can be found anywhere in body in this stage.

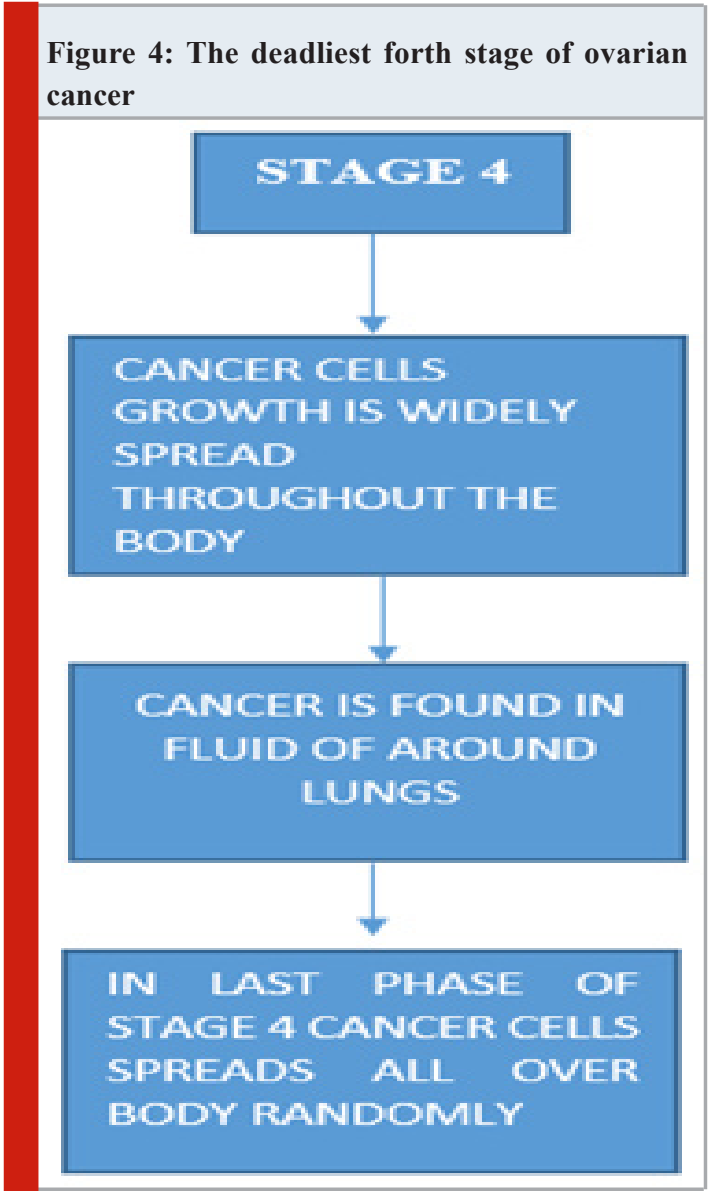

\subsection{Grades of Tumor}

Among all above four stages, third stage is most critical stage and in forth stage it become much difficult to save a cancer patient. In this disease, various grades have been categorized for tumor such as:

- GX: Tumor of this grade cannot be evaluated.it is very difficult to perform evaluation of GX category of tumor.

- GB: this is the category considered for borderline tumor. Also, known as low malignant potential that is (LPM).

- G1: in this category of tumor, cancer tissues can be easily recognized which looks like healthy tissue cells.

- G2: in this section, the tissue is differentiated with more difficulties \& major part of the cells looks abnormal.

- G3 - G4: due to tumor cells of this grade, the tissues are hardly able to differentiated. More and more tissues look abnormal and much rarely, any tissue is found healthy and normal(MD ANDERSON CANCER CENTRE et. at.).

Figure 5: Treatment given to stage 1 and 2 cancer patients.

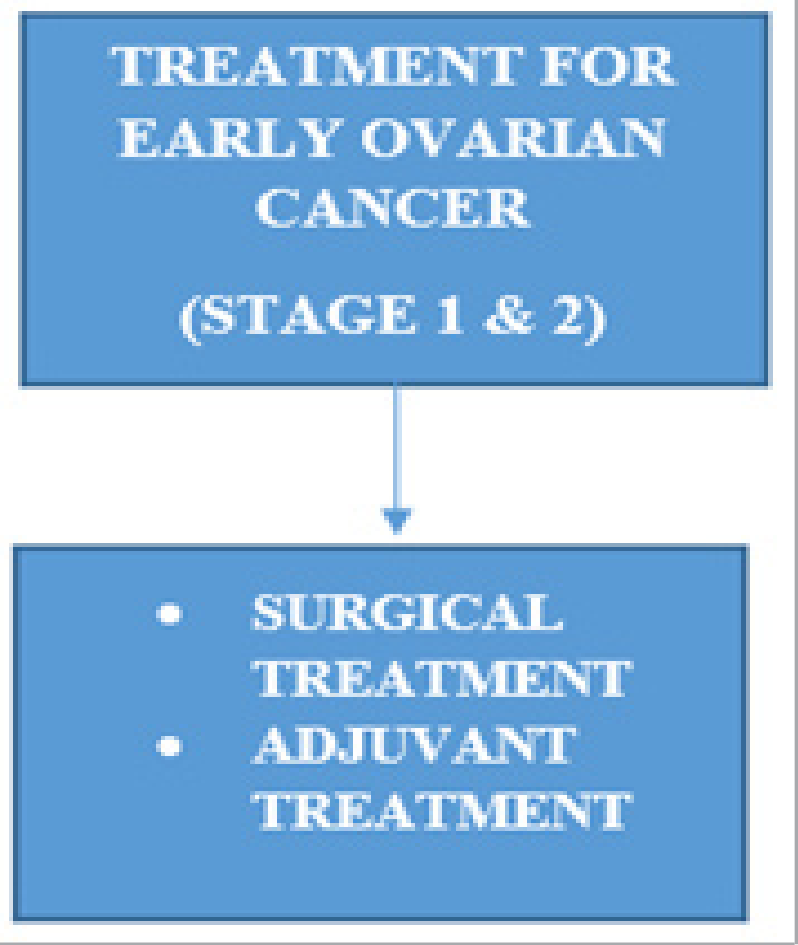

Figure 6: Treatment for FIGO stage 3 and 4

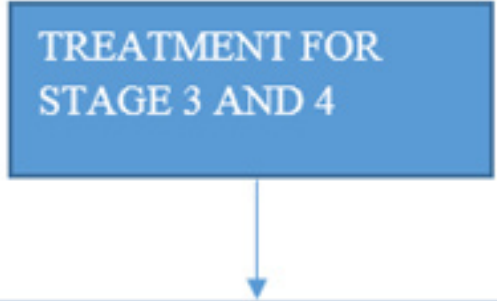

1.) Primary De-Bulking Surgery

2.) Interval De-Bulking Surgery

3.) Laparoscopy

4.) Primary Chemotherapy

5.) Salvage Treatment

6.) Secondary-Cytoreductive Surgery 
2.2. Test to Detect Ovarian Cancer: There are two major test examination to detect the early sign of ovarian cancer in INDIA that are given as below:

- CA125 - It is basically cancer antigen125 test which is a type of blood test in which early signs of ovarian cancer can be detected. This test is most accurate method to detect ovarian cancer cells till now. Reference range for this test is around 0 to 35 units per ml. (M. J. Duffy et. al (2005)).

- X-RAY/CT-SCAN - By examining the pelvic area using an X-ray or a CT scan is another process to test the ovarian cancer, however this test cannot found small cancer cells but it can detect the large tumor in ovarian tissues.

- $\quad$ TVUS - It is known as transvaginal ultrasound which works on sound waves to look at uterus and pelvic areas.

Table 1. Assessment on randomly selected women regarding ovarian cancer and their responses provided in respect of parameters.

\begin{tabular}{|c|c|c|c|c|c|}
\hline $\begin{array}{l}\text { Names } \rightarrow \\
\text { Parameters } \downarrow\end{array}$ & $\begin{array}{l}\text { Samira } \\
\text { Chauhan } \\
\text { (S1) }\end{array}$ & $\begin{array}{l}\text { Neha } \\
\text { Aggarwal } \\
\text { (S2) }\end{array}$ & $\begin{array}{l}\text { Christina } \\
\text { Edam } \\
\text { (S3) }\end{array}$ & $\begin{array}{c}\text { Ansy } \\
\text { Loiuse } \\
\text { (S4) }\end{array}$ & $\begin{array}{c}\text { Deepa } \\
\text { Manglik } \\
\text { (S5) }\end{array}$ \\
\hline Age & 25 & 32 & 35 & 41 & 45 \\
\hline Obesity & NO & Post Pregnancy & $\begin{array}{c}\text { Lower Abdomen } \\
\text { Swelling }\end{array}$ & NO & Yes \\
\hline $\begin{array}{l}\text { Weight } \\
\text { Overweight }\end{array}$ & 40 & 70 & 72 & 50 & 83 \\
\hline Health Issues & Acne & Weight Increased & Fast Heartbeat & Back Pain & Diabetic, Bp \\
\hline Physical Activities & Dance Yoga & Very Less & Not At All & Zumba, Gym & None \\
\hline Smoking & No & Once In 6 Month & 3 To 5 In A Month & Very Rare & 2Or 3 In A Weak \\
\hline Pelvic Pain & Occasionally & $\begin{array}{l}\text { Slight Pain Once } \\
\text { In A Month }\end{array}$ & $\begin{array}{l}\text { Stomach \& } \\
\text { Pelvic Pain }\end{array}$ & Very Often & $\begin{array}{l}\text { Yes Most } \\
\text { Of The Time }\end{array}$ \\
\hline Bloating & No & & Yes & No & YES \\
\hline Cancer History & No Cancer History & No & Paternal Aunt & No One & Maternal Uncle \\
\hline Irregularity Of M Cycle & Regular & Irregular Once In 3 Month & Irregular & Once In 6 Month & Irregular \\
\hline Suggestion & Fit \& Healthy & $\begin{array}{l}\text { Do Yoga And Exercise } \\
\text { And Improve } \\
\text { Eating Habits }\end{array}$ & $\begin{array}{l}\text { Go For A Routine } \\
\text { Checkup And } \\
\text { Reduce Weight }\end{array}$ & $\begin{array}{c}\text { Maintain Health } \\
\text { In A Healthy } \\
\text { Way }\end{array}$ & $\begin{array}{l}\text { Consult With } \\
\text { Gynecologist } \\
\text { And Obs. }\end{array}$ \\
\hline
\end{tabular}

2.3. Treatments Of Ovarian Cancer: The treatment given to treat and cure the ovarian cancer is also critical as because of the reason that, same treatment cannot be given for all stage patient. Therefore, different type of treatment is given to cancer patient associated with different cancer stage as illustrated in Figre $5 \& 6$. The different types of stagesare known as FIFO stages. For stage 1 and stage 2 that are initial stage of cancer two types of treatment is given that are illustrated in Figure 5. For FIGO stage 1 and stage 2, only surgical treatment is suggested for $\mathrm{C}$ type patient which is well differentiated phases from stage 1 up to stage $2 \mathrm{~A}$. In third and fourth stage of cancer above treatments are used (Figure 6). From all of these chemotherapy is ono of the most common treatment given by majority of doctors. In chemotherapy, cancer cells are aimed to kill by slow poison chemicals inserted drop wise in patient's body.

3. Literature Review: Christine Stewart et.al has purposed a review on ovarian cancer in related paper. Classification of types of ovarian cancer. Author has done discussion on risk factors, prevention, diagnoses and treatments of ovarian cancer. In this paper, author has presented her views on long term survivorship of ovarian cancer. Histopathology has been reviewed by author in different views. Author has mentioned lack of vitamin, active D3 with low vitamin $\mathrm{d}$ or b12 and smoking habits are major cause to develop cancer(C. ChristineStewart et. al (2019).

U. Matulonis et.al has described ovarian cancer in 5 different subpart with histological subtypes that has various risk factors and molecular properties with multiple clinical features. Author has described that ovarian cancer is a global problem which is diagnosed typically at a late phase or stage. Standard surgery treatment and platinum based chemotherapy can be given to newly diagnosed patients. According to author, high grade serous carcinoma that is (HGSC) is one of the most commonly used method of treatment given for diagnosing ovarian cancer which is most responsive(U. A. Matulonis et. al (2016).

A.Pines et.al has discussed regarding diet and nutrition habits that plays a vital role in daily life. Author mentioned in related paper that physical activity is one of the most important factor of life.With Benefits of exercise, one can improve lifestyle and its effect can be demonstrated in multiple body organs as per author discussion. There is positive effect of even mild and moderate physical activities on breast cancer and ovarian cancer(A. Pines et. al (2009). 
Figure 7: Conclusion of Assessment in a Cyclic Nature

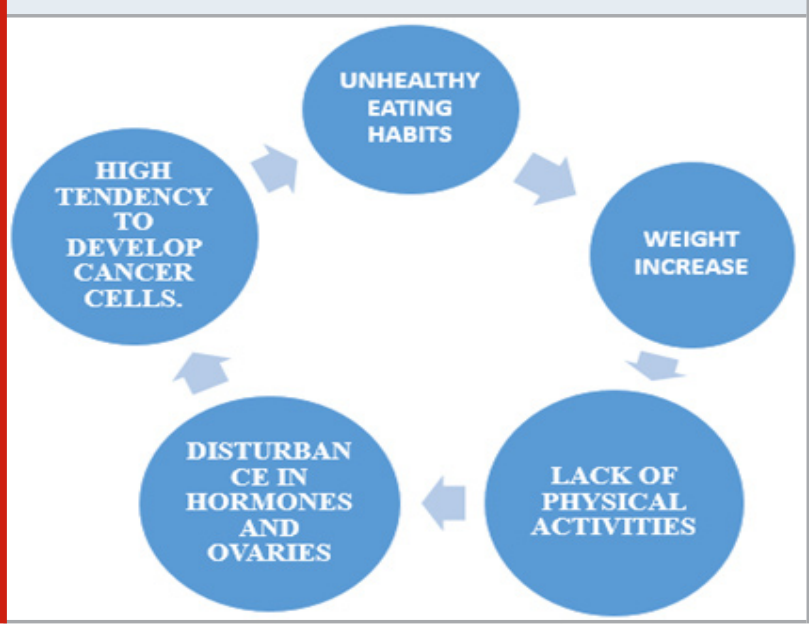

\section{METHODOLOGY}

An assessment has been done on randomly selected females at nearby metro station. Few parameters have been selected for this questionnaire and these questions were asked to randomly selected women in order to perform survey regrading ovarian cancer.

\subsection{Parameters for assessment:}

- Age

- Obesity

- Weight

- Physical activities

- Irregularity of menstrual cycle

- Any health issues facing already

- Pelvic pain

- Eating habits

- Bloating

- Cancer history

These are some of the major parameters on the basis of which the assessment is performed on selected women. On the basis of responses provided by samples (women) the appropriate suggestion was provided to them. Below is the table of associated response that describes the data for assessment. The main idea behind this assessment is that selected females has been asked few questions on the basis of which, some suggestions were provided to them. All the females have been classified in to two categories. First category consists of those females who persists healthy eating habits and regularly do physical activities such as any kind of yoga or body exercise or dance classes or swimming. Second category is of those females who has unhealthy eating habits and hardly they do physical exercise activities. On the basis of these two categories, it has been concluded who is at more risk of developing cancer cells and who is at lower risk of developing cancer cells. Because when we do physical activities and perform sports activities, cancer cells die and do not growto form cancer tissues which ultimately hamper and ruin the overall health of females.

5. Result Of Assessment: Below are the details that has been obtained from five females during assessment and their responses regarding defined parameters given as:

\section{CONCLUSION \& FUTURE PERSPECTIVE}

From the above assessment survey Table 1, it is concluded that females who maintain their weight and healthy eating habits in daily life are at low risk to develop cancer cells. The practicing of daily physical activities like exercise and yoga, gym, stretching, activities like dance helps to kills the bad fat in body and sweat releasing property burn carbohydrates which help to build strong muscles in body which results in healthy lifestyle. More the healthy lifestyle will be, lesser are the chances of female's tendency to develop cancer cells in body. On other hand, (Christina Edam \& Deepa Manglik) who do not practice any physical activities and exercise unhealthy eating habits are at a very close risk to develop the cancer cells because unsaturated fat deposited in thick layer makes the whole body weight increase and female feels lethargic whole day, lack of energy, which insist to move towards junk food and unhealthy eating habits. Cancer cells will develop at a high pace and lack of weight management and physical activities ruins the overall health of females. Irregularity of the menstrual cycle is one the major cause that disturb the overall functioning of ovaries and reproductive system in females.In Figure7 the process is illustrated in a cyclic nature as illustrated below:

From future perspectives, some points that can be shared with females to prevent them from ovarian cancer are listed below because if awareness is not well spread and information is not shared with more and more no. of females as well as males, then it may lead to more cases of ovarian cancers. Therefore, some major steps can be taken to prevent females from ovarian cancer like:

1. Attending free health awareness camps

2. Adopt healthy eating habits

3. Do regular exercise

4. Read blogs about ovarian cancer on internet.

By following these steps in daily routine, females can take care of their health and can prevent from developing not only ovarian cancer but, any kind of cancer.

\section{REFERENCES}

Biggs, J.S.G., 1981. Polycystic ovarian disease - current concepts. Australian and New Zealand Journal of Obstetrics and Gynaecology, 21(1), pp.26-36.

Chen, V.W., Ruiz, B., Killeen, J.L., Coté, T.R., Wu, X.C., Correa, C.N. and Howe, H.L., 2003. Pathology and classification of ovarian tumors. Cancer: Interdisciplinary International Journal of the American Cancer Society, 97(S10), pp.2631-2642.

Duffy, M.J., Bonfrer, J.M., Kulpa, J., Rustin, G.J.S., Soletormos, G., Torre, G.C., Tuxen, M.K. and Zwirner, M., 2005. CA125 in ovarian cancer: European Group on Tumor Markers guidelines for clinical use. International Journal of Gynecologic Cancer, 15(5). 
Forstner, R., 2020. Early detection of ovarian cancer. Matulonis, U.A., Sood, A.K., Fallowfield, L., Howitt, B.E., Sehouli, J. and Karlan, B.Y., 2016. Ovarian cancer. Nature reviews Disease primers, 2(1), pp.1-22.

Olson, S.H., Mignone, L., Nakraseive, C., Caputo, T.A., Barakat, R.R. and Harlap, S., 2001. Symptoms of ovarian cancer. Obstetrics \& Gynecology, 98(2), pp.212-217.

Pines, A., 2009. Lifestyle and diet in postmenopausal women. Climacteric, 12(sup1), pp.62-65.

Siegel, R.L., Miller, K.D. and Jemal, A., 2019. Cancer statistics, 2019. CA: a cancer journal for clinicians, 69(1), pp.7-34.

Stewart, C., Ralyea, C. and Lockwood, S., 2019, April. Ovarian cancer: an integrated review. In Seminars in oncology nursing (Vol. 35, No. 2, pp. 151-156). WB Saunders.

Twickler, D.M. and Moschos, E., 2010. Ultrasound and assessment of ovarian cancer risk. American Journal of Roentgenology, 194(2), pp.322-329. 